\title{
Synthesis and X-ray structure analysis of a heptacoordinate titanium(IV)-bis-chelate with enhanced in vivo antitumor efficacy $\dagger$
}

\author{
Timo A. Immel, ${ }^{a}$ Martin Grützke, ${ }^{a}$ Anne-Katrin Späte, ${ }^{a}$ Ulrich Groth ${ }^{a}{ }^{a}$ Peter Öhlschläger* ${ }^{*}$ \\ and Thomas Huhn*a
}

Received 4th March 2012, Accepted 16th April 2012

DOI: $10.1039 / \mathrm{c} 2 \mathrm{cc} 31624 \mathrm{~b}$

Chelate stabilization of a titanium(Iv)-salan alkoxide by ligand exchange with 2,6-pyridinedicarboxylic acid (dipic) resulted in heptacoordinate complex 3 which is not redox-active, stable on silica gel and has increased aqueous stability. 3 is highly toxic in HeLa S3 and Hep G2 and has enhanced antitumor efficacy in a mouse cervical-cancer model.

Diamino bis(phenolato) complexes of titanium(Iv) are, besides cyclopentadienyl- ${ }^{1}$ and diketonato-derivatives, ${ }^{2}$ a third class of anti-cancer active $\mathrm{Ti}^{\mathrm{IV}}$ species with a maximum in vitro cytotoxicity in the lower $\mu \mathrm{M}$-regime. ${ }^{3,4}$ The ligand is the hydrogenated form of the salicylaldimine (salen) and is for brevity often referred to as salan. ${ }^{5}$ The salan, a dianionic $\kappa^{2} O, \kappa^{2} N$ ligand, usually coordinates the $\mathrm{Ti}^{\mathrm{IV}}$ in a $f a c-f a c$-fashion, thus generating distorted octahedral $C_{2}$-symmetrical complexes, with the two remaining coordination sites occupied by monodentate alkoxides. A serious problem in the field of bioactive $\mathrm{Ti}^{\mathrm{IV}}$ complexes is the pronounced oxophilicity of $\mathrm{Ti}^{\mathrm{IV}}, 6$ which makes them susceptible to hydrolysis; ${ }^{7}$ e.g. hydrolytic instability was one issue in the application of titanocene dichloride and budotitane which ultimately led to a stop of the clinical trials. ${ }^{1 b, d}$ After the introduction of $\mathrm{Ti}^{\mathrm{IV}}$ halo-salan alkoxides as purely apoptotic cell death inducing agents, ${ }^{8}$ we recently demonstrated the beneficial effect of the halogen-substituent on aqueous stability ${ }^{9}$ and in vivo toxicity in a cervical-cancer mouse-model. ${ }^{10}$ In NMR-experiments in aqueous THF halflives of up to $300 \mathrm{~h}$ have been achieved. ${ }^{11}$ However, the formation of polynuclear $\mu \mathrm{O}$-bridged species with no bioactivity remaining was observed when higher concentrations of water were used. ${ }^{12}$ To date, attempts to gain access to more resistant and still bioactive titanium-salan complexes have been limited to manipulations at the salan only. A successful modification of the labile ligands toward a hydrolytic resistant and at

${ }^{a}$ Fachbereich Chemie and Konstanz Research School Chemical Biology, Universität Konstanz, Universitätsstr. 10, D-78457 Konstanz,

Germany.E-mail: thomas.huhn@uni-konstanz.de;

Fax: + 49-7531-884424; Tel: + 49-7531-882283

${ }^{b}$ Fachbereich Chemie und Biotechnologie, Fachhochschule Aachen,

Heinrich-Mußmann-Str., D-52428 Jülich, Germany.

E-mail:oehlschlaeger@fh-aachen.de

t Electronic supplementary information (ESI) available: Experimental details, crystallographic data for 3 and 4 , and supplementary figures. CCDC 804777 (3) and 804775 (4). For ESI and crystallographic data in CIF or other electronic format see DOI: 10.1039/c2cc31624b

the same time highly bioactive titanium-salan complex is still missing.

Inspired by our recent results with carboxylate based bi- and tridentates and their beneficial influence on the stability and cytotoxicity of titanocene derivatives, ${ }^{13}$ we became interested in the influence a second chelating agent might have on stability and cytotoxicity of $\mathrm{Ti}^{\mathrm{IV}}$-salan complexes when replacing both alkoxides. Even though several dicarboxylate-substituted cyclopentadienyl-complexes have been synthesized over the last few years, ${ }^{14}$ none such dicarboxylate is known in the field of salan complexes.

Herein we report the functionalization of a $\mathrm{Ti}^{\mathrm{IV}}-$ salan with the dianionic tridentate 2,6-pyridinedicarboxylic acid (dipic), a meridional ligand increasing the coordinative saturation at the titanium centre (Scheme 1).

The ligand exchange reaction was initiated by the addition of THF to an equimolar mixture of complex 1 and dipic 2 (Scheme 1). The reaction set in at once, visible by an immediate color change from bright yellow to dark red. The heterogeneous mixture became homogeneous over the course of several hours. ${ }^{1} \mathrm{H}-\mathrm{NMR}$ spectra recorded to monitor the consumption of starting material showed the formation of $3 \ddagger$ as a single new, well defined product. A similar reaction of $\mathbf{1}$ with methanol generated the previously unknown $\left[\mathrm{Ti}\left(\mathrm{Ph}^{\mathrm{Mc}} \mathrm{N}^{\mathrm{Me}}\right)_{2}(\mathrm{OMe})_{2}\right]$ (4). Analytical pure 3 was isolated by standard column chromatography on silica gel with ethyl acetate-petroleum ether as eluent in $90 \%$ yield.

The spectral features of $\mathbf{3}$ and $\mathbf{4}$ clearly resemble the spectrum of the starting material with respect to the amount and multiplicity of signals with the marked addition of the respective dipic and methoxy resonances. Apparently, the coordination of the salan had not been changed, $\mathrm{Ti}^{\mathrm{IV}}$ in 3

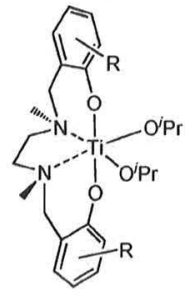

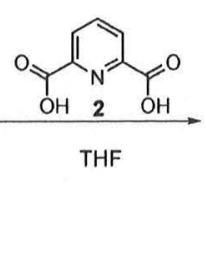

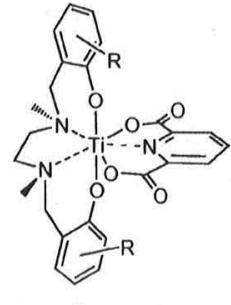

Scheme 1 Labile ligand exchange reaction of salan 1 with 2,6pyridinedicarboxylic acid $\mathbf{2}$ yielding heptacoordinate $\mathbf{3}$. 
and $\mathbf{4}$ is still fac-fac coordinate. $\mathbf{3}$ shows distinct singlets at $2.07,2.10$ and $2.41 \mathrm{ppm}$, the former two representing four arylbound methyl groups, the latter one the two nitrogen-bound methyl groups. Two singlets at 6.40 and $6.64 \mathrm{ppm}$ standing for two salan-bound protons each. The resonances of dipic appear as doublet at $6.70 \mathrm{ppm}$ and triplet at $7.54 \mathrm{ppm}$. Single crystals of 3 suitable for X-ray structure determination were isolated from a NMR sample in aqueous THF which was used to study hydrolysis over the course of several weeks (see below). The crystal structure of 3 confirmed the interpretation of the NMR data. 3 crystallizes in the monoclinic space group $P 2_{1} / c$, with one molecule in the asymmetric unit and no additional solvent. The titanium-centre in $\mathbf{3}$ is heptacoordinate and adopts a distorted pentagonal-bipyramidal conformation in the solid state. The three nitrogen atoms (N1-N3) and the two carboxylate oxygen atoms $(\mathrm{O} 3, \mathrm{O} 4)$ are forming the equatorial plane (greatest deviation from the mean: $0.2681(14) \AA$ for O4), the two phenolate oxygen atoms $(\mathrm{O} 1, \mathrm{O} 2)$ are located in the apical position and the salan-backbone is thus oriented in a fac-fac-fashion.

As expected, the dipicolinic acid acts as tridentate, ${ }^{14 g, h, 15}$ coordinating to the titanium-salan fragment via two of the carboxylate $\mathrm{O}$ atoms and its pyridine $\mathrm{N}$ atom (Fig. 1). With 2.0459(12) $\AA$ and 2.0428(13) $\AA$ the Ti-O3 and Ti-O4 distances are considerably shorter than comparable bonds in the titanocene dipicolinate $(2.11-2.15 \AA)$, while the $\mathrm{Ti}-\mathrm{N}$ distance is surprisingly unaffected $(2.1850(14) \AA$ compared to $2.16-2.18 \AA) .{ }^{14 h, 16}$ Interestingly, the plane of the pyridine ring is not coplanar with the equatorial plane defined by $\mathrm{O} 3, \mathrm{O} 4, \mathrm{~N} 1-\mathrm{N} 3$, both planes are twisted by $16.69(8)^{\circ}$. A slight rotation of the carboxylategroups by $3.1(2)^{\circ}(\mathrm{O} 3)$ and $7.2(2)^{\circ}(\mathrm{O} 4)$ out of the pyridine plane toward the titanium centre thus leads to a shortening of the titanium-carboxylate distance. Occupation of a fifth coordination site in the equatorial plane results in a compression of the N1-Ti-N2 angle to $73.48(5)^{\circ}$ (Fig. 2) in 3 compared with 75.4-76.6 for the alkoxy substituted 2,4-dimethyl salans.

Hydrolytic stability was investigated by time resolved ${ }^{1} \mathrm{H}-\mathrm{NMR}$ in aqueous $\left[\mathrm{D}_{8}\right] \mathrm{THF}$ (for details see ESI $\dagger$ ). Whereas 1 and 4 under these conditions had half-lives of $10 \mathrm{~h}^{9}$ and $8.5 \mathrm{~h}, 3$ proved to be extraordinarily stable. After a $38 \mathrm{~h}$ period at $37{ }^{\circ} \mathrm{C}$ no signs of degradation were visible by NMR, the sample stayed perfectly transparent with no precipitation occurring. Even after 2 weeks of continuous storage at $37{ }^{\circ} \mathrm{C}$

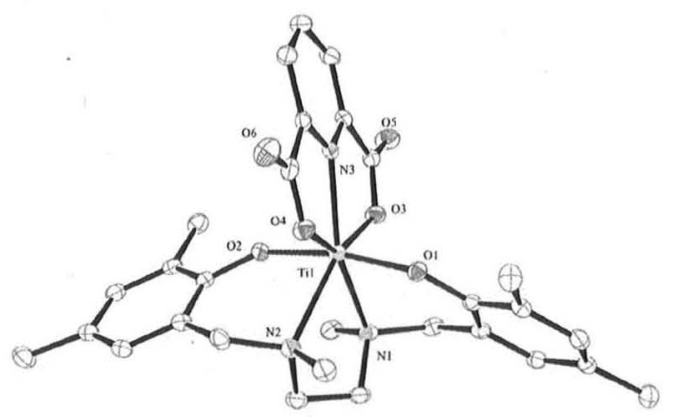

Fig. 1 X-ray crystal structure of the heptacoordinate $\left[\mathrm{Ti}\left(\mathrm{Ph}^{\mathrm{Me}} \mathrm{N}^{\mathrm{Me}}\right)_{2}\right.$ (dipic)] (3) exhibiting approximate $C_{2}$ symmetry and a distorted pentagonal-bipyramidal conformation of the ligands around the $\mathrm{Ti}^{\mathrm{IV}}$ centre. Thermal ellipsoids are drawn at the $50 \%$ probability level. Hydrogen atoms are omitted for clarity.

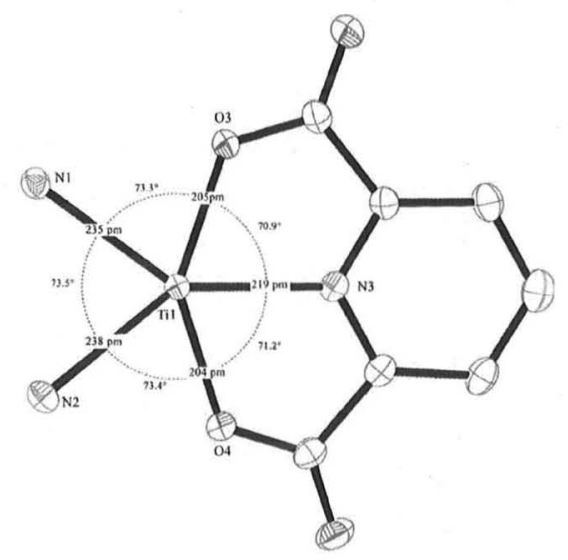

Fig. 2 Details from the molecular structure of $\left[\mathrm{Ti}\left(\mathrm{Ph}^{\mathrm{Me}} \mathrm{N}^{\mathrm{Me}}\right)_{2}(\right.$ dipic $\left.)\right]$ (3) showing a projection of the equatorial plane with N1, N2 of the salan, dipic and the fivefold coordinate $\mathrm{Ti}^{\mathrm{IV}}$-centre. Thermal ellipsoids are drawn at the $50 \%$ probability level; hydrogen atoms and most part of the salan ligand are omitted for clarity.

and the addition of another 1000 equivalents of $\mathrm{D}_{2} \mathrm{O}$ the sample remained unchanged. The increased stability of $\mathbf{3}$ compared to $\mathbf{1}$ and 4 might be rationalized by the modified geometry around the titanium centre. All five ligands in the equatorial plane of the pentagonal bipyramidal coordinate $\mathrm{Ti}^{\mathrm{iV}}$ are placed at the corners of a nearly perfect equilateral pentagon (Fig. 2). This, together with the $f a c-f a c$ arranged salan, perfectly encloses the titanium centre allowing even the purification of $\mathbf{3}$ by gravity column chromatography on silica gel with ordinary stock-solvents in high yield. Cyclic voltammetry of 3 in the $\mathrm{CH}_{2} \mathrm{Cl}_{2} / \mathrm{NBu}_{4} \mathrm{PF}_{6}(0.1 \mathrm{M})$ supporting electrolyte at $\mathrm{rt}\left(\mathrm{Cp}_{2} \mathrm{Fe}^{0 /+}\right.$ couple as reference) revealed a complete absence of redox processes between -1.8 and $+1.8 \mathrm{~V}$.

The cytotoxicity of $\mathbf{3}$ was analyzed by the AlamarBlue assay ${ }^{17}$ against its parent complex $\mathbf{1}$ and the Ti-OMe derivative 4 in two different human cancer cell lines: cervix-carcinoma HeLa S3, and hepato-carcinoma Hep G2. This study revealed high activity of all three complexes (Table 1). Complexes 1 and 4 showed slightly higher toxicity in both cell lines compared to 3. A direct correlation of cytotoxicity with the estimated half-lives of the complexes was not apparent.

To investigate the efficacy of $\mathbf{3}$ compared to $\mathbf{4}$ in an in vivo model of cervical cancer, ${ }^{18} \mathrm{C} 3$ tumor bearing mice received either 3 or $\mathbf{4}$ in a low dose regime over multiple applications (Table 2). Both complexes were well tolerated and no adverseeffects were observed. At day 35 the groups receiving complexes 3 and $\mathbf{4}$ showed a reduced tumor growth compared to the control group. In the group receiving complex 3,6 out of 10 mice had a dramatically reduced tumor size $\left(8 \pm 3 \mathrm{~mm}^{2}\right)$

Table $1 \mathrm{IC}_{50}$-values obtained by an AlamarBlue assay in HeLa S3 and Hep G2 cells and half-life estimated by time resolved ${ }^{1} \mathrm{H}-\mathrm{NMR}$ of complexes 1,3 and 4

\begin{tabular}{llll}
\hline & $\mathrm{IC}_{50}(\mathrm{HeLa} \mathrm{S} 3)^{a}$ & $\mathrm{IC}_{50}($ Hep G2) & $t_{1 / 2}{ }^{b}$ \\
\hline $\mathbf{1}$ & $2.3 \pm 0.1$ & $2.1 \pm 0.1$ & $10 \mathrm{~h}$ \\
$\mathbf{3}$ & $4.4 \pm 0.4$ & $3.4 \pm 0.3$ & $\gg 2$ weeks \\
$\mathbf{4}$ & $3.7 \pm 0.8$ & $2.2 \pm 0.2$ & $8.5 \mathrm{~h}$ \\
cis-Platin & $1.2 \pm 0.4$ & $3.0 \pm 1.3$ & -
\end{tabular}

a All $\mathrm{IC}_{50}$-values given are means from at least three independent experiments each done in four replicates. ${ }^{b}$ Details are given in the ESI. 
Table 2 Growth of established C3 tumors in mice after multipledose-treatment with complexes 3 and $\mathbf{4}(n=10$ mice per group). Mice were treated on days $0,2,5,8,11,14\left(5 \mathrm{mg} \mathrm{kg}^{-1}\right)$ and tumor sizes were measured using a sliding caliper. The experiment was terminated at day 35 . One representative of two experiments is shown

\begin{tabular}{llll}
\hline & $\begin{array}{l}\text { Average tumor } \\
\text { size at day 0 } \\
\left(\mathrm{mm}^{2}\right) \pm \text { SEM }\end{array}$ & $\begin{array}{l}\text { Average tumor } \\
\text { size at day 35 } \\
\left(\mathrm{mm}^{2}\right) \pm \text { SEM }\end{array}$ & $\begin{array}{l}\text { Number of } \\
\text { total regressors } \\
\text { at day 35 }\end{array}$ \\
\hline Control $^{a}$ & $2 \pm 1$ & $267 \pm 28$ & 0 \\
4 & $3 \pm 1$ & $63 \pm 11$ & 0 \\
3 & $4 \pm 2$ & $8 \pm 3$ & 4 \\
${ }^{a}$ DMSO/PBS/0.5\% Tween80. & \\
\hline
\end{tabular}

and moreover, $40 \%$ total tumor regressors (no tumor palpable) were documented. Interestingly, the group receiving the higher cytotoxic $\mathbf{4}$ showed no total regressor and the average tumor size was estimated to be $63 \pm 11 \mathrm{~mm}^{2}$. Reduction of tumor growth has already been achieved by us in a recent study when using a high-dose treatment with $\mathrm{T}_{1}{ }^{\mathrm{IV}}$ halo-salan alkoxides, albeit dose dependent adverse-effects like loss of hair and apathy were observed in the effective treatment regime $\left(50 \mathrm{mg} \mathrm{kg}^{-1}\right) .^{10}$ The dipic stabilized $\mathbf{3}$ in contrast to the $\mathrm{Ti}^{\mathrm{IV}}$ halo-salan alkoxides is well tolerated and shows an improved efficacy already at lower doses $\left(30 \mathrm{mg} \mathrm{kg}^{-1}\right)$. A higher hydrolytic stability in the range of several days has a beneficial effect on tolerability and efficacy of $\mathrm{Ti}^{\mathrm{IV}}$-salan complexes in vivo compared to cell proliferation assays, where complexes are administered directly on tumor cells and thus aqueous stability is of less importance. The fact that hydrolysis of $\mathbf{3}$ in aqueous THF is severely impeded does not rule out a ligand exchange with biomolecules under in vitro/ in vivo conditions. However, in contrast to $\mathrm{Ti}^{\mathrm{IV}}-$ salan complexes with monodentate alkoxo-ligands this process will proceed comparably slower in the case of the dipic stabilized $\mathbf{3}$, thus maintaining higher levels of bioavailable 3 for a prolonged time and giving 3 the opportunity to find the 'right' cellular target.

In summary, we have presented the synthesis, structural elucidation by NMR and X-ray data analysis, hydrolysis study and biological evaluation in vitro and in vivo of the exceedingly stable tridentate substituted $\mathrm{Ti}^{\mathrm{IV}}-\operatorname{salan}\left[\mathrm{Ti}\left(\mathrm{Ph}^{\mathrm{Me}} \mathrm{N}^{\mathrm{Me}}\right)_{2}\right.$ (dipic) $]$ (3). The pyridine-2,6-dicarboxylato-ligand efficiently stabilizes the titanium(Iv) in aqueous media, resulting in a $C_{2}$ symmetric complex which neither decomposes during several weeks of incubation in aqueous THF nor exhibits electrochemical activity. Even though, $\mathbf{3}$ was slightly less active in a cell proliferation assay, it outperformed its parent complex $\mathbf{1}$ in an in vivo study in mice. 4 mice out of 10 exhibited total tumor regression at day 35 , Table 2. Further studies are currently underway to extend the concept of stabilizing cytotoxic $\mathrm{Ti}^{\mathrm{IV}}$-salan complexes with different additional chelators to access highly cytotoxic agents with good in vivo tolerability and efficacy.

The authors are grateful to Malin Bein for help with the cell based assays and Philipp Mücke for the redox-chemistry measurements. Generous financial support of the Konstanz Research School Chemical Biology is gratefully acknowledged (personal scholarship to T.A.I.).

\section{Notes and references}

$\ddagger$ Crystal data for 3 (CCDC 804777): $\mathrm{C}_{29} \mathrm{H}_{33} \mathrm{~N}_{3} \mathrm{O}_{6} \mathrm{Ti}, M=567.48$, monoclinic, $a=9.2989(6) \AA, b=22.7397(17) \AA, c=14.9120(10) \AA$, $\beta=122.978(4)^{\circ}, V=2645.2(3) \AA^{3}, T=100(2) \mathrm{K}$, space group $P 2_{1} / c$, $Z=4,25319$ reflections measured, 5643 independent reflections $\left(R_{\text {int }}=0.0520\right)$. The final $R_{1}$ values were $0.0364(I>2 \sigma(I))$. The final $w R\left(F^{2}\right)$ values were $0.0794(I>2 \sigma(I))$. The final $R_{1}$ values were 0.0543 (all data). The final $w R\left(F^{2}\right)$ values were 0.0839 (all data). Crystal data for 4 (CCDC 804775): $\mathrm{C}_{24} \mathrm{H}_{36} \mathrm{~N}_{2} \mathrm{O}_{4} \mathrm{Ti}, M=464.45$, triclinic, $a=$ $11.2918(7) \AA, b=11.8315(8) \AA, c=18.3210(12) \AA, \alpha=98.082(5)^{\circ}$, $\beta=102.992(5)^{\circ}, \gamma=97.181(5)^{\circ}, V=2330.0(3) \AA^{3}, T=100(2) \mathrm{K}$ space group $P \overline{1}, Z=4,33475$ reflections measured, 9894 independent reflections $\left(R_{\text {int }}=0.0428\right)$. The final $R_{1}$ values were $0.0333(I>2 \sigma(I))$. The final $w R\left(F^{2}\right)$ values were $0.0859(I>2 \sigma(I))$. The final $R_{1}$ values were 0.0438 (all data). The final $w R\left(F^{2}\right)$ values were 0.0892 (all data).

1 (a) P. Köpf-Maier and H. Köpf, Anticancer Res., 1986, 6, 227-233; (b) P. M. Abeysinghe and M. M. Harding, Dalton Trans., 2007, 3474-3482; (c) K. Strohfeldt and M. Tacke, Chem. Soc. Rev., 2008, 37, 1174-1187; (d) E. Meléndez, Crit. Rev. Oncol. Hematol., 2002, 42, 309-315; (e) S. Eger, T. A. Immel, J. Claffey, H. Müller-Bunz, M. Tacke, U. Groth and T. Huhn, Inorg. Chem., 2010, 49, 1292-1294.

2 B. Keppler, C. Friesen, H. Moritz, H. Vongerichten and E. Vogel, Struct. Bonding (Berlin, Ger.), 1991, 71, 97-127.

3 (a) M. Shavit, D. Peri, C. M. Manna, J. S. Alexander and E. Y. Tshuva, J. Am. Chem. Soc., 2007, 129, $12098-12099 ;(b)$ E. Y. Tshuva and J. A Ashenhurst, Eur. J. Inorg. Chem., 2009, 2203-2218; (c) E. Y. Tshuva and D. Peri, Coord. Chem. Rev., 2009, 253, 2098-2115.

4 A comprehensive overview on the bioinorganic chemistry of titanium is given in: K. M. Buettner and A. M. Valentine, Chem. Rev., 2012, 112, 1863-1881.

5 (a) D. A. Atwood, Coord. Chem. Rev., 1997, 165, 267-296; (b) D. A. Atwood, J. Benson, J. A. Jegier, N. F. Lindholm, K. J. Martin, R. J. Pitura and D. Rutherford, Main Group Chem., 1995, 1, 99-113.

6 J. P. Gaffney and A. M. Valentine, Dalton Trans., 2011, 40, 5827-5835.

7 J. H. Toney and T. J. Marks, J. Am. Chem. Soc., 1985, 107, 947-953. 8 T. A. Immel, M. Debiak, U. Groth, A. Bürkle and T. Huhn, ChemMedChem, 2009, 4, 738-741.

9 T. A. Immel, U. Groth and T. Huhn, Chem.-Eur. J., 2010, 16, 2775-2789.

10 T. A. Immel, U. Groth, T. Huhn and P. Öhlschläger, PLoS One, 2011, 6, e17869.

11 D. Peri, S. Meker, C. M. Manna and E. Y. Tshuva, Inorg. Chem., 2011, 50, 1030-1038.

12 D. Peri, S. Meker, M. Shavit and E. Y. Tshuva, Chem.-Eur. J., 2009, 15, 2403-2415.

13 T. A. Immel, J. T. Martin, C. J. Dürr, U. Groth and T. Huhn, J. Inorg. Biochem., 2010, 104, 863-867.

14 (a) T. Krüger, C. Wagner, T. Lis, R. Kluge, W. Mörke and D. Steinborn, Inorg. Chim. Acta, 2006, 359, 2489-2494; (b) T. Krüger, C. Albrecht, T. Rüffer, H. Lang, J. Griebel, R. Kirmse and D. Steinborn, Z. Anorg. Allg. Chem., 2008, 634, 1030-1034; (c) C. Albrecht, T. Krüger, C. Wagner, T. Rüffer, H. Lang and D. Steinborn, Z. Anorg. Allg. Chem., 2008, 634, 2495-2503; (d) I. Fichtner, D. Behrens, J. Claffey, B. Gleeson, M. Hogan, D. Wallis, H. Weber and M. Tacke, Lett. Drug Des. Discovery, 2008, 5, 489-493; (e) J. Claffey, M. Hogan, H. Müller-Bunz, C. Pampillón and M. Tacke, ChemMedChem, 2008, 3, 729-731; (f) J. Claffey, A. Deally, B. Gleeson, S. Patil and M. Tacke, Appl. Organomet. Chem., 2010, 24, 675 679; (g) R. Fandos, B. Gallego, A. Otero, A. Rodriguez, M. J. Ruiz, P. Terreros and C. Pastor, Dalton Trans., 2006, 2683-2690; (h) R. Leik, L. Zsolnai, G. Huttner, E. W. Neuse and H. H. Brintzinger, J. Organomet. Chem., 1986, 312, 177-182.

15 (a) D. Schwarzenbach, Inorg. Chem., 1970, 9, 2391-2397; (b) D. Schwarzenbach, Helv. Chim. Acta, 1972, 55, 2990-3004 (c) H. Manohar and D. Schwarzenbach, Helv. Chim. Acta, 1974, 57, 1086-1095; (d) M. Shavit and E. Y. Tshuva, Eur. J. Inorg. Chem., 2008, 1467-1474.

16 (a) P. D. Kheirollahi, H. Aghabozorg and A. Moghimi, X-Ray Struct. Anal. Online, 2005, 21, 153-154; (b) C.-X. Ren, F.-T. Chen and G.-X. Jin, Wuji Huaxue Xuebao, 2006, 22, 1473-1478.

17 R. Hamid, Y. Rotshteyn, L. Rabadi, R. Parikh and P. Bullock, Toxicol. In Vitro, 2004, 18, 703-710.

18 M. C. W. Feltkamp, H. L. Smits, M. P. M. Vierboom, R. P. Minnaar, B. M. De Jongh, J. W. Drijfhout, J. T. Schegget, C. J. M. Melief and W. M. Kast, Eur. J. Immunol., 1993, 23, 2242-2249. 